\title{
MicroReview
}

\section{A golden shot: how ballistic single cell transformation boosts the molecular analysis of cereal-mildew interactions}

\author{
RALPH PANSTRUGA* \\ Max-Planck-Institut für Züchtungsforschung, Department of Plant Microbe Interactions, Carl-von-Linné-Weg 10, 50829 Köln, Germany
}

\section{SUMMARY}

Despite considerable technical progress in past years, genetic manipulation of cereals remains a tedious task. Thus, transgenic approaches in monocot species to study plant-microbe interactions are limited to date. Transient gene expression in single epidermal cells mediated by particle bombardment has emerged recently as an attractive alternative for testing the impact of (over-)expressing or silencing single host genes in the context of cereal-powdery mildew interactions. The ease and pace of this assay enables the analysis of candidate genes within a fraction of the time needed to generate stable transgenic lines. Genetically encoded fluorescent sensors expressed in single cells are ideally suited to monitor gene expression, subcellular protein localization and changes of physiological parameters at the single cell level. Likewise, single cell gene expression can be employed to study protein-protein interactions of fluorophoretagged polypeptides by fluorescence resonance energy transfer or fluorescence (cross) correlation spectroscopy. An integrated approach, combining single cell gene expression technology with modern cell biological tools and single cell sampling via laser capture microdissection, may provide in-depth insights into the molecular events in epidermal host cells in the course of cerealmildew interactions.

\section{INTRODUCTION}

Compared with the dicotyledonous model species Arabidopsis thaliana, knowledge of molecular components involved in plantmicrobe interactions of the agronomically relevant Triticeae species is still limited. One reason for this is the enormous size of cereal genomes, which renders gene discovery by map position a formidable task, even in the era of synteny-assisted cloning using

*Correspondence: Tel.: +49 (0)221 5062-316; Fax: +49 (0)221 5062-353;

E-mail: panstrug@mpiz-koeln.mpg.de the sequenced rice genome as a reference. In addition, the generation time of monocot species like barley (Hordeum vulgare) and bread wheat (Triticum aestivum) is comparatively long, routine transformation is not yet widely established, and hexaploidy of bread wheat causes further complications in molecular and genetic analyses. Thus, to date only a limited number of genes involved in plant-microbe interactions have been molecularly isolated from Triticeae species, including the barley defence modulator Mlo (Büschges et al., 1997), various alleles of the complex Mla resistance gene locus (Halterman et al., 2001, 2003; Halterman and Wise, in press; Shen et al., 2003; Wei et al., 2002; Zhou et al., 2001), resistance modulating genes Rar1 (Shirasu et al., 1999a) and Ror2 (Collins et al., 2003), as well as the barley and wheat rust resistance genes Rpg1 (Brueggeman et al., 2002) Lr21 (Huang et al., 2003) and Lr10 (Feuillet et al., 2003), respectively. Likewise, only a limited number of transgenes have been tested for their effect on cereal-microbe interactions. These include, for example, transgenic plants constitutively expressing a stilbene synthase gene encoding the phytoalexin resveratrol (Fettig and Hess, 1999; Leckband and Lörz, 1998), an apoplastic barley-seed class II chitinase (Bliffeld et al., 1999), an apoplasttargeted seed ribosome-inactivating protein (RIP; Bieri et al., 2000), barley class II chitinase, barley type I RIP, or the anti-fungal protein Ag-AFP from Aspergillus giganteus (Oldach et al., 2001), apoplastic barnase and $\beta-1,3$ glucanase (Bieri et al., 2003) as well as transgenic barley lines expressing the Rpg1 stem rust resistance gene (Horvath et al., 2003). In addition to the cerealspecific difficulties outlined above, general problems of transgene expression in stably transformed plants (e.g. somaclonal variation, transcriptional or post-transcriptional gene silencing) may cause further complications.

The technical and biological limitations that currently restrict a broad analysis of the role of candidate host genes in cerealmicrobe interactions might be partially overcome by transient gene expression technology that allows a rapid assessment of potential anti-fungal proteins and/or host compatibility factors. Currently employed methods for transient gene expression in plant specimens include protoplast transfection, Agrobacterium 
infiltration, viral vectors and particle bombardment (Fischer et al., 1999). A transient gene expression method that recently became common for studying cereal-mildew interactions is based on ballistic transformation of single leaf epidermal cells and subsequent challenge inoculation of transformed samples with powdery mildew conidiospores.

In this review, I summarize the application of this procedure for the molecular analysis of cereal-powdery mildew interactions. Advantages as well as limitations of this approach are emphasized and potential future adaptations of the basic scheme for sophisticated cell biological studies in the context of plant-microbe interactions are portrayed.

\section{A brief history of ballistic plant transformation}

The first successful delivery of nucleic acid-coated microprojectiles into plant tissue (onion, Allium cepa) via a particle inflow gun was reported more than 15 years ago (Klein et al., 1987). At that time, the major intention was to develop an alternative method for stable plant transformation, circumventing the host-range restrictions of Agrobacterium tumefaciens and the regeneration problems of protoplast transformation. Since then, particle guns have been used in numerous studies for the generation of stably transformed plants and/or transient expression analyses in a variety of plant species and tissues (reviewed in Finer et al., 1999).

Nelson and Bushnell (1997) were the first to suggest exploiting transient single cell gene expression in a cereal host species for the analysis of plant-pathogen interactions. They demonstrated that neither the particle bombardment itself nor the expression of a reporter gene in single epidermal cells of barley (Hordeum vulgare) coleoptiles interfered with the development of powdery mildew (Blumeria graminis f. sp. hordei) infection structures when conidiospores were inoculated on the coleoptiles following particle bombardment. The basic method was subsequently simplified by using detached first leaves of wheat (Triticum aestivum) or barley seedlings instead of prepared coleoptiles for the ballistic procedure (Nielsen et al., 1999; Schweizer et al., 1999b; Shirasu et al., 1999b). Since then, various laboratories have used this basic set-up for studying the impact of (over-)expressing or silencing candidate genes on the outcome of cereal-powdery mildew interactions (see below and Table 1).

\section{Transient gene expression in single epidermal cells: a rapid means for probing host candidate genes in cereal-powdery mildew interactions}

The generalized experimental procedure of the single cell transient expression assay used to study cereal-powdery mildew interactions is shown in Fig. 1. Briefly, detached leaf sections are co-bombarded with DNA-coated particles carrying a reporter as well as a test gene construct. Following powdery mildew challenge, pathogen success is evaluated at individual interaction sites on single epidermal cells that are highlighted by marker gene expression. Quantification of pathogen success in relation to a control gene transformation indicates the impact of the test gene on the outcome of the host-pathogen interaction (Fig. 1).

This experimental approach is particularly suited for the analysis of cereal-powdery mildew interactions for several reasons. First, the outcome of cereal-powdery mildew interactions appears to be governed exclusively in a cell-autonomous manner, an important prerequisite for applying single cell gene expression analysis. Second, Blumeria graminis solely attacks epidermal cells (the primary target tissue of particle bombardment), and its infection structures (with the exception of the 'intracellular' haustoria) grow completely epiphytic and develop in a highly synchronous manner. This enables a reproducible and convenient evaluation of infection success by microscopy of stained fungal structures. Furthermore, powdery mildew conidiospores can be easily generated in excessive amounts, and cereal epidermal cells are comparatively large. The latter two features ensure that on average nearly every transformed cell will be attacked by a fungal sporeling, if an adequate inoculation density $\left(\sim 200\right.$ conidia/ $\left.\mathrm{mm}^{2}\right)$ is applied.

During the past 5 years, the procedure described above has been used extensively to study various types of interactions between cereals and powdery mildew: basal defence/basal compatibility as occurring in susceptible wild-type plants (Kristensen et al., 2001; Schultheiss et al., 2002; Schweizer et al., 1999a,b), isolate-specific resistance mediated by prototypical resistance $(R)$ genes of the coiled-coil nucleotide binding-leucine rich repeat (CC-NB-LRR) class (Halterman et al., 2001, 2003; Halterman and Wise, in press; Shen et al., 2003; Zhou et al., 2001), broad spectrum resistance conferred by recessive mutant alleles $(\mathrm{m} / \mathrm{o})$ of the barley Mlo locus (Elliott et al., 2002; Hückelhoven et al., 2003; Kim et al., 2002; Shirasu et al., 1999b) and also forma specialis incompatibility to an 'inappropriate' cereal powdery mildew species (Elliott et al., 2002). Experiments included complementation analyses of plant mutants involving either the native gene (e.g. barley Mlo, Shirasu et al., 1999b) or orthologues and/or paralogues thereof (e.g. rice and wheat orthologues of barley Mlo (Elliott et al., 2002) or the Arabidopsis PEN1 orthologue of barley Ror2 (Collins et al., 2003)). In addition, single amino acid mutant variants or domain swap constructs were used for structure-function analyses of the respective polypeptides, as demonstrated for members of the wheat germin-like protein family (Schweizer et al., 1999a), the calmodulin binding domain of barley Mlo (Kim et al., 2002), or barley Mla1, Mla6, Mla7 and Mla13 resistance genes (Halterman and Wise, in press; Shen et al., 2003).

\section{Hush! Gene silencing in single cells}

Besides gain-of-function experiments by (over-)expressing genes of interest, the single cell assay has been adopted for 
Table 1 Compilation of host genes assayed for their functional contribution to the outcome of cereal-powdery mildew interactions by means of transient single cell gene expression. *

\begin{tabular}{|c|c|c|c|c|c|c|}
\hline $\begin{array}{l}\text { Putative functional } \\
\text { category }\end{array}$ & $\begin{array}{l}\text { Gene } \\
\text { (Speciest) }\end{array}$ & $\begin{array}{l}\text { Putative function of } \\
\text { encoded protein }\end{array}$ & $\begin{array}{l}\text { Bombarded } \\
\text { speciest }\end{array}$ & $\begin{array}{l}\text { Overexpression (+)/ } \\
\text { silencing (-) }\end{array}$ & $\begin{array}{l}\text { Effect on penetration } \\
\text { efficiency } \dagger\end{array}$ & Reference \\
\hline \multirow{8}{*}{$\begin{array}{l}\text { Cell death } \\
\text { regulation }\end{array}$} & $M l o(H v)$ & Defence modulator & $H v(m / o)$ & + & $\uparrow$ (complementation) & Shirasu et al. (1999b) \\
\hline & Mlo $(H v)$ & Defence modulator & $H v$ & + & $\uparrow$ (super-susceptibility) & Kim et al. (2002) \\
\hline & Mlo $(H v)$ & Defence modulator & $H V$ & - & $\downarrow(50 \%)$ & Schweizer et al. (2000) \\
\hline & Mlo2B (Ta) & Defence modulator & $H v(m / o)$ & + & $\uparrow$ (complementation) & Elliott et al. (2002) \\
\hline & Mlo2(Os) & Defence modulator & $H v(m / o)$ & + & $\uparrow$ (complementation) & Elliott et al. (2002) \\
\hline & $\operatorname{Baxl}(H v)$ & Bax inhibitor & $H v$ & + & $\uparrow(165 \%)$ & Hückelhoven et al. (2003) \\
\hline & $\operatorname{Baxl}(H v)$ & Bax inhibitor & $H v$ & - & $\approx$ & Hückelhoven et al. (2003) \\
\hline & $\operatorname{Baxl}(H v)$ & Bax inhibitor & $H v(m / o)$ & + & $\uparrow(520 \%)$ & Hückelhoven et al. (2003) \\
\hline \multirow{12}{*}{$\begin{array}{l}\text { Defence-related } \\
\text { genes }\end{array}$} & gf $2.8(\mathrm{Ta})$ & Germin & Ta & + & $\downarrow(50 \pm 6 \%)$ & Schweizer et al. (1999a) \\
\hline & GLP1 (Ta) & Germin-like protein & $\mathrm{Ta}$ & + & $\approx(112 \pm 9 \%)$ & Schweizer et al. (1999a) \\
\hline & $G L P 2(T a)$ & Germin-like protein & $\mathrm{Ta}$ & + & $\downarrow(56 \pm 6 \%)$ & Schweizer et al. (1999a) \\
\hline & WIR1 $(T a)$ & Unknown & $\mathrm{Ta}$ & + & $\approx(135 \pm 17 \%)$ & Schweizer et al. (1999b) \\
\hline & WIR2 (Ta) & Thaumatin-like protein & $\mathrm{Ta}$ & + & $\approx(97 \pm 12 \%)$ & Schweizer et al. (1999b) \\
\hline & WIR3 (Ta) & Peroxidase & $\mathrm{Ta}$ & + & $\downarrow(30 \pm 9 \%)$ & Schweizer et al. (1999b) \\
\hline & WCI5 (Ta) & Unknown & $\mathrm{Ta}$ & + & $\downarrow(81 \pm 3 \%)$ & Schweizer et al. (1999b) \\
\hline & Gluc (Ta) & $\beta-1,3$ glucanase & $\mathrm{Ta}$ & + & $\approx(114 \pm 12 \%)$ & Schweizer et al. (1999b) \\
\hline & $\mathrm{CH} 26(\mathrm{Ta})$ & Chitinase & $\mathrm{Ta}$ & + & $\downarrow(76 \pm 10 \%)$ & Schweizer et al. (1999b) \\
\hline & $G O X(T a)$ & Glucose oxidase & Ta & + & $\downarrow(63 \pm 10 \%)$ & Schweizer et al. (1999b) \\
\hline & $\operatorname{Prx} 7 \mathrm{~S}(\mathrm{Hv})$ & Peroxidase & $H V$ & + & $\uparrow(193 \%)$ & Kristensen et al. (2001) \\
\hline & $\operatorname{Pr} \times 8 S(H v)$ & Peroxidase & $H v$ & + & $\approx(89 \%)$ & Kristensen et al. (2001) \\
\hline \multirow{6}{*}{$\begin{array}{l}\text { Intracellular } \\
\text { signalling }\end{array}$} & $\operatorname{Rar1}(H v)$ & Defence signalling & $H V$ & - & $\uparrow$ & Azevedo et al. (2002) \\
\hline & Sgt1 $(H v)$ & Defence signalling & $H v$ & - & $\uparrow$ & Azevedo et al. (2002) \\
\hline & $\mathrm{CaM}(H v)$ & Calcium sensor & $H v$ & + & $\uparrow$ & Kim et al. (2002) \\
\hline & $\mathrm{CaM}(H v)$ & Calcium sensor & $H v$ & - & $\downarrow(45 \pm 13 \%)$ & Kim et al. (2002) \\
\hline & $G \alpha(H v)$ & $\mathrm{G}$ protein subunit & $H v$ & $+/-$ & $\approx$ & Kim et al. (2002) \\
\hline & $R A C B(H v)$ & Small G-protein & $H v$ & - & $\downarrow$ & Schultheiss et al. (2002) \\
\hline \multirow[t]{7}{*}{ Resistance genes } & Mla1 $(H v)$ & CC-NB-LRR protein & $H V$ & + & $\downarrow$ (complementation) & Zhou et al. (2001) \\
\hline & Mla6 (Hv) & CC-NB-LRR protein & $H V$ & + & $\downarrow$ (complementation) & Halterman et al. (2001) \\
\hline & Mla6 (Hv) & CC-NB-LRR protein & $\mathrm{Ta}$ & + & $\downarrow$ (complementation) & Halterman et al. (2001) \\
\hline & Mla7 (Hv) & CC-NB-LRR protein & $H v$ & + & $\downarrow$ (complementation) & Halterman and Wise (in press) \\
\hline & Mla10 (Hv) & CC-NB-LRR protein & $H v$ & + & $\downarrow$ (complementation) & Halterman and Wise (in press) \\
\hline & Mla12(Hv) & CC-NB-LRR protein & $H v$ & + & $\downarrow$ (complementation) & Shen et al. (2003) \\
\hline & Mla13 $(H v)$ & CC-NB-LRR protein & $H v$ & + & $\downarrow$ (complementation) & Halterman et al. (2003) \\
\hline \multirow{2}{*}{$\begin{array}{l}\text { Vesicle } \\
\text { traffic }\end{array}$} & $\operatorname{Ror2}(H v)$ & Syntaxin & Hv (mlo ror 2$)$ & + & $\downarrow$ (complementation) & Collins et al. (2003) \\
\hline & PEN1 (At) & Syntaxin & Hv (mlo ror 2$)$ & + & $\downarrow$ (complementation) & Collins et al. (2003) \\
\hline
\end{tabular}

*This compilation lists representative results from the respective studies. Frequently, additional mutant variants of candidate genes were tested or genes were assayed in further genetic backgrounds.

$\dagger H v$, Hordeum vulgare (barley); Ta, Triticum aestivum (bread wheat); Os, Oryza sativa (rice), At, Arabidopsis thaliana.

$\ddagger \uparrow$, enhanced; $\downarrow$, reduced; $\approx$, unaltered; percentages given are relative to expression of a respective control construct.

loss-of-function experiments by gene silencing. Specific, homologydependent gene silencing in plants can be accomplished via double-stranded RNA interference (dsRNAi; Chuang and Meyerowitz, 2000; Schweizer et al., 2000). The dsRNA required for triggering subsequent degradation of target mRNAs can either be transcribed in vitro and subsequently delivered into target cells or provided by the transcription of inverted repeat DNA constructs.
The latter is frequently the method of choice because it is technically simple and supposed to mediate a continuous supply of dsRNA. Both, direct delivery of in vitro transcribed dsRNAs (Schultheiss et al., 2002; Schweizer et al., 2000) and expression of inverted repeat DNA constructs (Azevedo et al., 2002; Kim et al., 2002; Panstruga et al., 2003; Schweizer et al., 2000), have proved successful for gene silencing in single cereal epidermal 
A

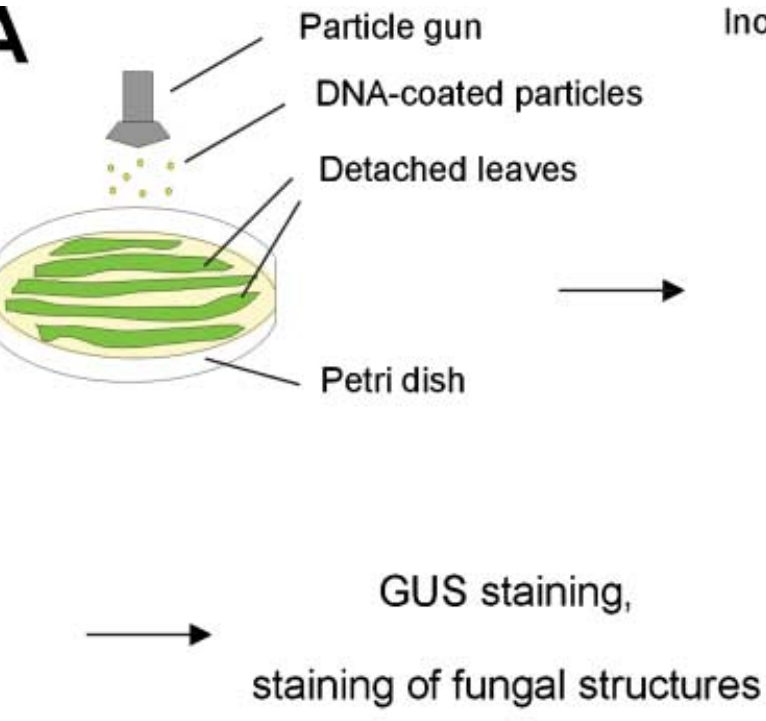

staining of fungal structures

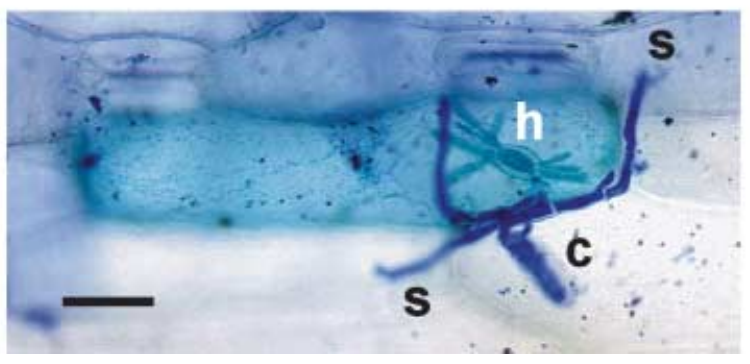

B noculation with powdery mildew spores
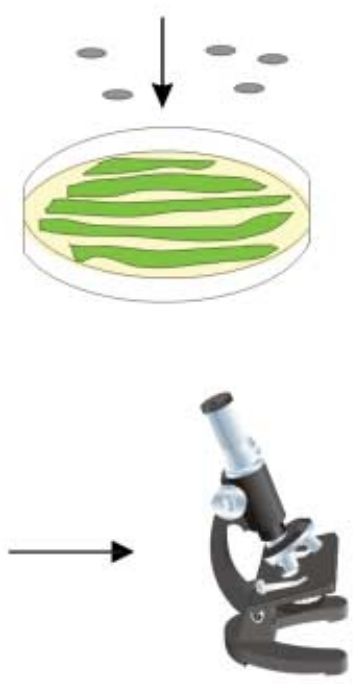

Microscopic evaluation

Fig. 1 Particle bombardment-mediated single cell gene expression as a tool for the molecular analysis of cereal-powdery mildew interactions. (A) Tungsten or gold particles coated with DNA of a reporter gene construct (to mark successfully transformed epidermal cells) and a test gene construct are co-bombarded into segments of detached first leaves of approximately 1-week-old barley or wheat seedlings. Acceleration of particles occurs by helium pressure under vacuum conditions. Depending on the experimental goal, leaf segments are inoculated $4-96 \mathrm{~h}$ post bombardment with a high-density $\left(\sim 200 \mathrm{conidia} / \mathrm{mm}^{2}\right)$ of powdery mildew conidiospores, resulting subsequently on average in one to several plant-fungal interaction sites per epidermal cell. Subject to the reporter gene used for marking successfully transformed epidermal cells, cells may either be stained for GUS activity about $48 \mathrm{~h}$ post inoculation (Nielsen et al., 1999; Schweizer et al., 1999b) or inspected for GFP fluorescence by epifluorescence microscopy (Nielsen et al., 1999; Shirasu et al., 1999b). In the former case, fungal infection structures can be stained by Coomassie Brilliant Blue, whereas in the latter case highlighting fungal structures with fluorescent dyes such as calcofluor is suitable (Hückelhoven et al., 2003; Schultheiss et al., 2002). The effect of a test gene on the plant-fungal interaction can be calculated based on microscopic evaluation. Successfully transformed epidermal cells (as marked by reporter gene expression) that are attacked by the appressorial germ tube of mildew conidia are quantified. Concomitantly, the proportion of these cells showing either host cell wall penetration (indicated by the presence of an 'intracellular' fungal haustorium) or the establishment of a compatible plant-microbe interaction (indicated by growth of secondary hyphae and/or completion of the asexual life cycle by sporulation) is recorded. The ratio of transformed cells enabling 'successful' fungal-plant interactions divided by the total number of attacked transformed cells is a measure of the impact of the test gene on the plant-fungal interaction. (B) Micrograph of a successful fungal penetration attempt on a ballistically transformed barley epidermal cell. A barley leaf was ballistically transformed with a GUS reporter construct as shown in A. Subsequently, the leaf was inoculated with powdery mildew conidia and, at $48 \mathrm{~h}$ post inoculation, stained for GUS activity. For microscopic evaluation, epiphytic fungal structures were highlighted by Coomassie Brilliant Blue. Successful penetration is indicated by presence of a haustorium and elongating secondary hyphae. c, conidiospore; h, haustorium; s, secondary hyphae. Scale bar $=20 \mu \mathrm{m}$.

cells (Table 1). A dual fluorescent reporter protein-based assay can be used to assess the potency of particular silencing constructs in a semiquantitative manner (Panstruga et al., 2003). Multiple dsRNAi constructs may be introduced simultaneously in single cereal cells without any obvious negative effect on the silencing efficiency. For example, co-silencing of barley Rar1 and Sgt1 in the same epidermal cells compromised race-specific resistance more effectively than silencing Rar1 or Sgt1 individually 
(Azevedo et al., 2002). Based on silencing of a test gene fused to the reporter green fluorescent protein (GFP), it was shown that as many as 30 additional inverted repeat DNA constructs affecting endogenous barley genes can be co-transformed into the same cell without interfering with dsRNAi-mediated silencing of the reporter construct (P. Schweizer, personal communication). However, the total number of bombarded cells expressing the GFP-coupled reporter protein seems to decrease with the number of additional dsRNAi constructs, possibly because of induced lethality of individual epidermal cells by silencing multiple endogenous genes simultaneously. Currently, we exploit the fact that a moderate number of co-silenced genes are tolerated without deleterious effects for an unbiased screen for genes involved in basal defence against powdery mildew in barley. In this approach, pools of dsRNAi constructs derived from a barley epidermal unigene CDNA set are investigated for causing elevated or reduced fungal penetration success. In this manner, a gene encoding an actin-depolymerizing factor (ADF) was identified as a crucial component of basal defence, broad-spectrum resistance governed by mlo alleles as well as nonhost resistance to inappropriate powdery mildew species, but not for isolate-specific resistance governed by race-specific $R$ genes (M. Miklis et al., unpublished results).

\section{Nothing is perfect: limitations of single cell analyses}

Although extremely powerful for the rapid analysis of candidate genes, it is evident that single cell gene expression bears intrinsic limitations. With respect to overexpression of candidate genes, target cells are assumed to be loaded with nonphysiological concentrations of DNA constructs coated to the ballistically introduced particle(s). Thus, even when using the native promoter for driving transgene expression, ectopic expression may not be avoided. Negative results of gene silencing experiments have to be interpreted with caution because the period allowed for turnover of pre-existing endogenous target protein is limited and might be too short to observe any phenotypic effect. A further limitation is that owing to the restricted number of transformed cells within a detached leaf sample, biochemical analyses following transgene expression are nowadays virtually impossible. Thus, complementing experiments involving either wild-type plants, transgenic plants or mutant plants affected in candidate gene(s) might be required. In this respect, the recent development of resources for reverse genetics in barley, e.g. a transposontagged population (Koprek et al., 2000) and a barley TILLING population (Scottish Crop Research Institute; R. Waugh, personal communication), might prove invaluable for the identification of mutant plants bearing lesions in a gene of interest.

It should be emphasized that appliance of single cell gene expression for studying other biological processes is restricted to cell-autonomous traits. In addition, the primary target tissue of particle bombardment is the epidermal cell layer, rendering the method largely unsuited for the analysis of biological processes in other cell types.

\section{The wonderful world of colours: fluorescent probes as invaluable tools for single cell studies}

Translational fusions with genetically encoded fluorophores such as GFP, yellow fluorescent protein (YFP), cyan fluorescent protein (CFP) or red fluorescing proteins (DsRED, monomeric RFP) are nowadays routinely used to study subcellular localizations of proteins of interest. Because plant epidermal cells contain no chloroplasts, subcellular targeting of fusion constructs can be visualized upon ballistic transformation of detached leaves by epifluorescence microscopy and/or confocal laser scanning microscopy (CLSM) without significant interference of background chlorophyll fluorescence. Successfully employed examples include expression of an MLO::GFP fusion protein (Shirasu et al., 1999b) as well as GFP fusions with several pathogen-induced proteins from wheat (germin, germin-like protein, WIR1-3, WCI5, a $\beta-1,3$ glucanase and a chitinase; Schweizer et al., 1999a,b). Common caveats for studying subcellular localization of ectopically expressed, fluorophore-tagged polypeptides include mistargeting as a result of overexpression, altered localization mediated by the fluorophore tag and loss of functionality. However, when interpreted with caution and accompanied by respective control experiments, such studies might prove useful to elucidate potential re-localization of candidate polypeptides upon pathogen attack.

Likewise, fluorescent marker proteins targeted to particular organelles might be employed as probes to highlight specific organelles/compartments ('organelle tagging'). This may reveal transport processes of these organelles/compartments in the course of a plant-pathogen interaction ('organelle flow'), as for example reported for the nucleus of attacked and neighbouring epidermal cells during fungal invasion (Schmelzer, 2002).

The availability of spectrally distinct fluorophore tags enables simultaneous labelling of multiple proteins/organelles within the same cell. Moreover, recently developed illumination-inducible fluorophore variants (reviewed in Zhang et al., 2003) may enable us to track the fate of a local protein/organelle subpopulation upon selective photochemical activation. In addition, protein::fluorophore fusions can be used as semiquantitative efficiency markers in gene silencing experiments, as successfully demonstrated in various studies (Azevedo et al., 2002; Kim et al., 2002; Panstruga et al., 2003; Schultheiss et al., 2002). Besides translational fusions to proteins, recently developed short-lived fluorophore variants (half-life $<2 \mathrm{~h}$ ) may be transcriptionally fused to a cereal promoter of interest to examine conditional (e.g. pathogen-triggered) gene activation (Zhang et al., 2003).

Pairs of fluorophore-tagged proteins can be employed to study noninvasively and in real time the dynamics of protein-protein 
interactions in living (plant) cells by fluorescence resonance energy transfer (FRET) analysis (reviewed in Hink et al., 2002). Imaging FRET requires that one polypeptide is tagged with a suitable donor fluorophore (e.g. CFP), while its interaction partner is tagged with a corresponding acceptor fluorophore (e.g. YFP). Using an appropriate excitation wavelength, nonradiative energy transfer between donor and acceptor fluorophores may be visualized upon close physical proximity of the two polypeptides of interest. Transient expression based on ballistic transformation of two respective fusion constructs in plant epidermal cells allows us to study the dynamics of protein-protein interactions upon pathogen attack. Sophisticated procedures such as acceptor photobleaching (APB) and fluorescence lifetime imaging (FLIM) permit quantification of protein-protein affinities (APB) as well as visualizing a spatial interaction profile (FLIM). We have successfully used FRET technology to analyse the dynamics of the previously described interaction between the barley defence modulator MLO and the cytoplasmic calcium sensor calmodulin (Kim et al., 2002) in single epidermal cells upon attack by powdery mildew sporelings (R. Bhat et al., unpublished results).

Further sophisticated spectrometric methods such as fluorescence correlation spectroscopy (FCS) and fluorescence crosscorrelation spectroscopy (FCCS) measure the diffusion rate of individual, fluorescently labelled molecules (reviewed in Hink et al., 2002). These techniques allow us to determine, at the single molecule level, whether a protein is part of a multiprotein complex (FCS) or whether two protein molecules co-migrate, indicative of physical interaction (FCCS).

A range of recently developed genetically encoded fluorescent probes are ideally suited for cell biological studies in the context of plant-microbe interactions. Among these are 'cameleon' proteins for the ratiometric quantification of cytoplasmic calcium levels via intramolecular FRET (Miyawaki et al., 1997). Cameleons consist of calmodulin fused to an M13 calmodulin-binding domain, sandwiched by CFP and YFP fluorophores. Alterations of cytoplasmic calcium concentration affect the affinity of M13 for calmodulin, inducing in turn conformational changes that modulate the intramolecular FRET efficiency between CFP and YFP fluorophores. Calcium ions are ubiquitous second messenger molecules assumed to play a pivotal role in cell signalling upon various physiological stimuli, including biotic stress (Sanders et al., 1999). Single cell expression of cameleon calcium indicators will allow recording the 'calcium signature', a characteristic 'fingerprint' of temporal and spatial changes in the cytosolic calcium concentration (Rudd and Franklin-Tong, 2001), in the course of cereal-powdery mildew interactions and its correlation with subsequent cellular events.

Conceptually related to cameleon proteins, fusion constructs have been developed that sandwich serine/threonine or tyrosine kinase target peptides between CFP and YFP (reviewed in Zhang et al., 2003). In these molecules, phosphorylation of the target peptide results in altered intramolecular FRET efficiency, thus indirectly reporting upstream kinase activation. Further fluorescent probes include $\mathrm{pH}$ - and halide-sensitive fluorophores for monitoring pH changes and ion fluxes (Zhang et al., 2003). Translational fusions of GFP with mouse talin (GFP::talin) can be employed for the visualization of the host actin cytoskeleton (Kost et al., 1998). Dynamic reorganization of cytoskeletal components such as actin filaments and microtubules has been observed upon pathogen attack in various plant-pathogen interactions (including those between cereals and powdery mildews), and it appears that the concomitant cell polarization is crucial for defence responses leading ultimately to resistance against host and nonhost pathogens (Kobayashi et al., 1997; Schmelzer, 2002; Skalamera and Heath, 1998; Yun et al., 2003).

\section{Sampling en miniature: extracting molecules from single cells}

Laser capture microdissection (LCM) is a method that enables sampling of single cells or a cell cluster from complex tissues (Emmert-Buck et al., 1996). The technique, originally developed for the analysis of animal tissues, was recently adapted for high-resolution spatial analysis of plant systems (Kehr, 2003; Kerk et al., 2003; Nakazono et al., 2003). Following LCM, molecules (e.g. RNA, proteins and metabolites) extracted from sampled cells can be profiled by suitable, sensitive analytical methods such as cDNA/oligonucleotide microarrays, two-dimensional polyacrylamide gel electrophoresis or mass spectrometry. The single cell resolution of LCM renders this technique an ideal supplement to single cell gene expression. (Semi-)automated sampling of particular cell types from cross-sections of fixed tissue (e.g. epidermal cells or mesophyll cells) will enable the detailed analysis of the transcriptome, proteome or metabolome of these cell types during compatible/and or incompatible plant-pathogen interactions. With respect to transcript profiling, the recent establishment of a barley microarray chip covering approximately 22000 unigenes represents a major technical achievement (Wise et al., 2003; Close and Wanamaker, 2003). If future refinements of CLM will enable sampling of individual cells from intact living tissue, then this progress will open new experimental routes by combining transient single cell gene expression methodology with single cell sampling technology.

\section{CONCLUSIONS}

Compared with conventional methods such as map-based cloning and generation of stably transformed plants, transient expression and/or silencing of candidate host genes in single epidermal cells has considerably boosted the molecular analysis of cereal-powdery mildew interactions during the past 5 years. This has enabled us to verify the role of host candidate genes, the 
identification of novel components, and the structure/function analysis of known proteins in compatible and incompatible interactions. However, the availability of novel sophisticated cell biological tools such as FRET and FC(C)S technology, a range of advanced genetically encoded fluorescent probes and laser capture microdissection methodology will allow us to enter a new level of experimental complexity. In the future, one-dimensional (expression/silencing of a single gene) studies will become less important, and creative experimental lines combining these new tools with single cell gene expression in various forms will come to the fore. In the long-term, such integrative approaches promise to dissect spatially and temporally the molecular events in a host cell during compatible and incompatible plant-biotroph interactions.

\section{ACKNOWLEDGEMENTS}

I am grateful to Elmon Schmelzer for critically reading the manuscript. Marco Miklis kindly provided the micrograph shown in Fig. 1B. Work in my laboratory is supported by grants from the Max-Planck society (MPG) and the Deutsche Forschungsgemeinschaft (DFG).

\section{REFERENCES}

Azevedo, C., Sadanandom, A., Kitagawa, K., Freialdenhoven, A., Shirasu, K. and Schulze-Lefert, P. (2002) The RAR1 interactor SGT1, an essential component of $R$ gene-triggered disease resistance. Science, 295, 2073-2076.

Bieri, S., Potrykus, I. and Fütterer, J. (2000) Expression of active barley seed ribosome-inactivating protein in transgenic wheat. Theor. Appl. Genet. 100, 755-763.

Bieri, S., Potrykus, I. and Fütterer, J. (2003) Effects of combined expression of antifungal barley seed proteins in transgenic wheat on powdery mildew infection. Mol. Breed, 11, 37-48.

Bliffeld, M., Mundy, J., Potrykus, I. and Fütterer, J. (1999) Genetic engineering of wheat for increased resistance to powdery mildew disease. Theor. Appl. Genet. 98, 1079-1086.

Brueggeman, R., Rostoks, N., Kudrna, D., Kilian, A., Han, F., Chen, J., Druka, A., Steffenson, B. and Kleinhofs, A. (2002) The barley stem rust-resistance gene $R p g 1$ is a novel disease-resistance gene with homology to receptor kinases. Proc. Natl Acad. Sci. USA, 99, 9328-9333.

Büschges, R., Hollricher, K., Panstruga, R., Simons, G., Wolter, M., Frijters, A., van Daelen, R., van der Lee, T., Diergaarde, P., Groenendijk, J., Töpsch, S., Vos, P., Salamini, F. and Schulze-Lefert, P. (1997) The barley Mlo gene: a novel control element of plant pathogen resistance. Cell, 88, 695-705.

Chuang, C.F. and Meyerowitz, E.M. (2000) Specific and heritable genetic interference by double-stranded RNA in Arabidopsis thaliana. Proc. Natl Acad. Sci. USA, 97, 4985-4990.

Close, T. and Wanamaker, S. (2003) The barley microarray. ASPB Plant Biology conference, Honolulu, Hawaii, Poster 1004 (http:// abstracts.aspb.org/pb2003/public/P59/0933.html).

Collins, N.C., Thordal-Christensen, H., Lipka, V., Bau, S., Kombrink, E., Qiu, J.-L., Hückelhoven, R., Stein, M., Freialdenhoven, A.,
Somerville, S.C. and Schulze-Lefert, P. (2003) SNARE-mediated disease resistance at the plant cell wall. Nature, 425, 973-977.

Elliott, C., Zhou, F., Spielmeyer, W., Panstruga, R. and Schulze-Lefert, P. (2002) Functional conservation of wheat and rice Mlo orthologs in plant defense modulation to powdery mildew. Mol. Plant Microbe Interact. 15, 1069-1077.

Emmert-Buck, M.R., Bonner, R.F., Smith, P.D., Chuaqui, R.F., Zhuang, Z., Goldstein, S.R., Weiss, R.A. and Liotta, L.A. (1996) Laser capture microdissection. Science, 274, 998-1001.

Fettig, S. and Hess, D. (1999) Expression of a chimeric stilbene synthase gene in transgenic wheat lines. Transgenic Res. 8, 179-189.

Feuillet, C., Travella, S., Stein, N., Albar, L., Nublat, A. and Keller, B. (2003) Map-based isolation of the leaf rust resistance gene Lr10 from the hexaploid wheat (Triticum aestivum L.) genome. Proc. Natl Acad. Sci. USA, 100, 15253-15258.

Finer, J.J., Finer, K.R. and Ponappa, T. (1999) Particle bombardment mediated transformation. Plant Biochtechnol. Curr. Topics Microbiol. Immunol. 240, 59-80.

Fischer, R., Vaquero-Martin, C., Sack, M., Drossard, J., Emans, N. and Commandeur, U. (1999) Towards molecular farming in the future: transient protein expression in plants. Biotechnol. Appl. Biochem. 30, 113-116.

Halterman, D.A., Wei, F. and Wise, R.P. (2003) Powdery mildew-induced Mla mRNAs are alternatively spliced and contain multiple upstream open reading frames. Plant Physiol. 131, 558-567.

Halterman, D.A. and Wise, R.P. (in press) A single amino acid substitution in the sixth leucine-rich repeat of barley MLA6 and MLA13 alleviates dependence on RAR1 for disease resistance signaling. Plant J.

Halterman, D., Zhou, F., Wei, F., Wise, R.P. and Schulze-Lefert, P. (2001) The MLA6 Coiled-Coil, NBS-LRR protein confers AvrMla6-dependent resistance specificity to Blumeria graminis f.sp. hordei in barley and wheat. Plant J. 25, 335-348.

Hink, M.A., Bisseling, T. and Visser, A. (2002) Imaging protein-protein interactions in living cells. Plant Mol. Biol. 50, 871-883.

Horvath, H., Rostoks, N., Brueggeman, R., Steffenson, B., von Wettstein, D. and Kleinhofs, A. (2003) Genetically engineered stem rust resistance in barley using the Rpg1 gene. Proc. Natl Acad. Sci. USA, 100, 364-369.

Huang, L., Brooks, S.A., Li, W.L., Fellers, J.P., Trick, H.N. and Gill, B.S. (2003) Map-based cloning of leaf rust resistance gene $L r 21$ from the large and polyploid genome of bread wheat. Genetics, 164, 655-664.

Hückelhoven, R., Dechert, C. and Kogel, K.H. (2003) Overexpression of barley BAX inhibitor 1 induces breakdown of mlo-mediated penetration resistance to Blumeria graminis. Proc. Natl Acad. Sci. USA, 100, 55555560.

Kehr, J. (2003) Single cell technology. Curr. Opin. Plant Biol. 6, 617-621.

Kerk, N.M., Ceserani, T.C., Tausta, L., Sussex, I.M. and Nelson, T.M. (2003) Laser capture microdissection of cells from plant tissues. Plant Physiol. 132, 27-35.

Kim, M.C., Panstruga, R., Elliott, C., Müller, J., Devoto, A., Yoon, H.W., Park, H., Cho, M.J. and Schulze-Lefert, P. (2002) Calmodulin interacts with MLO to regulate defence against mildew in barley. Nature, 416, 447-450.

Klein, T.M., Wolf, E.D., Wu, R. and Sanford, J.C. (1987) High-velocity microprojectiles for delivering nucleic acids into living cells. Nature, 327 70-73.

Kobayashi, Y., Kobayashi, I., Funaki, Y., Fujimoto, S., Takemoto, T. and Kunoh, H. (1997) Dynamic reorganization of microfilaments and 
microtubules is necessary for the expression of non-host resistance in barley coleoptile cells. Plant J. 11, 525-537.

Koprek, T., McElroy, D., Louwerse, J., Williams-Carrier, R. and Lemaux, P.G. (2000) An efficient method for dispersing Ds elements in the barley genome as a tool for determining gene function. Plant J. 24, 253-263.

Kost, B., Spielhofer, P. and Chua, N.H. (1998) A GFP-mouse talin fusion protein labels plant actin filaments in vivo and visualizes the actin cytoskeleton in growing pollen tubes. Plant J. 16, 393-401.

Kristensen, B.K., Ammitzboll, H., Rasmussen, S.K. and Nielsen, K.A. (2001) Transient expression of a vacuolar peroxidase increases susceptibility of epidermal barley cells to powdery mildew. Mol. Plant Pathol. 2, 311-317.

Leckband, G. and Lörz, H. (1998) Transformation and expression of a stilbene synthase gene of Vitis vinifera $\mathrm{L}$. in barley and wheat for increased fungal resistance. Theor. Appl. Genet. 96, 1004-1012.

Miyawaki, A., Llopis, J., Heim, R., McCaffery, J.M., Adams, J.A., Ikura, M. and Tsien, R.Y. (1997) Fluorescent indicators for $\mathrm{Ca}^{2+}$ based on green fluorescent proteins and calmodulin. Nature, 388, 882-887.

Nakazono, M., Qiu, F., Borsuk, L.A. and Schnable, P.S. (2003) Laser capture microdissection, a tool for the global analysis of gene expression in specific plant cell types: identification of genes differently expressed in epidermal cells or vascular tissues of maize. Plant Cell, 15, 583-596.

Nelson, A.J. and Bushnell, W.R. (1997) Transient expression of anthocyanin genes in barley epidermal cells: potential for use in evaluation of disease response genes. Transgenic Res. 6, 233-244.

Nielsen, K., Olsen, O. and Oliver, R. (1999) A transient expression system to assay putative antifungal genes on powdery mildew infected barley leaves. Physiol. Mol. Plant Pathol. 54, 1-12.

Oldach, K.H., Becker, D. and Lörz, H. (2001) Heterologous expression of genes mediating enhanced fungal resistance in transgenic wheat. Mol. Plant-Microbe Interact. 14, 832-838.

Panstruga, R., Kim, M.C., Cho, M.J. and Schulze-Lefert, P. (2003) Testing the efficiency of dsRNAi-constructs in vivo: a transient expression assay based on two fluorescent proteins. Mol. Biol. Report, 30, 135-140.

Rudd, J.J. and Franklin-Tong, V.E. (2001) Unravelling response-specificity in $\mathrm{Ca}^{2+}$ signalling pathways in plant cells. New Phytol. 151, 7-33.

Sanders, D., Brownlee, C. and Harper, J.F. (1999) Communicating with calcium. Plant Cell, 11, 691-706.

Schmelzer, E. (2002) Cell polarization, a crucial process in fungal defence. Trends Plant Sci. 7, 411-415.

Schultheiss, H., Dechert, C., Kogel, K.H. and Hückelhoven, R. (2002) A small GTP-binding host protein is required for entry of powdery mildew fungus into epidermal cells of barley. Plant Physiol. 128, 1447-1454.
Schweizer, P., Christoffel, A. and Dudler, R. (1999a) Transient expression of members of the germin-like gene family in epidermal cells of wheat confers disease resistance. Plant J. 20, 540-552.

Schweizer, P., Pokorny, J., Abderhalden, O. and Dudler, R. (1999b) A transient assay system for the functional assessment of defense-related genes in wheat. Mol. Plant-Microbe Interact. 12, 647-654.

Schweizer, P., Pokorny, J., Schulze-Lefert, P. and Dudler, R. (2000) Double-stranded RNA interferes with gene function at the single-cell level in cereals. Plant J. 24, 895-903.

Shen, Q.-H., Bieri, S., Zhou, F., Haizel, T., Shirasu, K. and SchulzeLefert, P. (2003) Recognition specificity and RAR1/SGT1 dependency in barley Mla disease resistance genes to the powdery mildew fungus. Plant Cell, 15, 732-744.

Shirasu, K., Lahaye, T., Tan, M.W., Zhou, F.S., Azevedo, C. and SchulzeLefert, P. (1999a) A novel class of eukaryotic zinc-binding proteins is required for disease resistance signaling in barley and development in $C$. elegans. Cell, 99, 355-366.

Shirasu, K., Nielsen, K., Piffanelli, P., Oliver, R. and Schulze-Lefert, P. (1999b) Cell-autonomous complementation of mlo resistance using a biolistic transient expression system. Plant J. 17, 293-299.

Skalamera, D. and Heath, M.C. (1998) Changes in the cytoskeleton accompanying infection-induced nuclear movements and the hypersensitive response in plant cells invaded by rust fungi. Plant J. 16, 191200.

Wei, F.S., Wong, R.A. and Wise, R.P. (2002) Genone dynamics and evolution of the Mla (powdery mildew) resistance locus in barley. Plant Cell, 14, 1903-1917.

Wise, R.P., Caldo, R.A., Turner, S.M., Ashlock, D.A. and Dickerson, J.A. (2003) Parallel expression profiling of gene-for-gene specified responses in barley-powdery mildew interactions. 7th International Congress on Plant Molecular biology, Barcelona, Spain, Poster S21-51 (http:// www.ispmb2003.com/).

Yun, B.W., Atkinson, H.A., Gaborit, C., Greenland, A., Read, N.D., Pallas, J.A. and Loake, G.J. (2003) Loss of actin cytoskeletal function and EDS1 activity, in combination, severely compromises non-host resistance in Arabidopsis against wheat powdery mildew. Plant J. 34, 768-777.

Zhang, J., Campbell, R.E., Ting, A.Y. and Tsien, R.Y. (2003) Creating new fluorescent probes for cell biology. Nature Rev. Mol. Cell Biol. 4, 906918.

Zhou, F., Kurth, J., Wei, F., Elliott, C., Valè, G., Yahiaoui, N., Keller, B., Somerville, S., Wise, R. and Schulze-Lefert, P. (2001) Cell-autonomous expression of barley Mla1 confers race-specific resistance to the powdery mildew fungus via a Rar1-independent signalling pathway. Plant Cell, 13, 337-350. 